\title{
Sociobiology
}

SHORT NOTE

\section{Neotropical Swarm-Founding Wasps (Vespidae: Polistinae: Epiponini) Accept Expelled Queens in Case of Queen Loss}

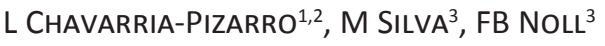 \\ 1 - Escuela de Biología, Instituto Tecnológico de Costa Rica, Cartago, Costa Rica \\ 2 - Departamento de Biologia, FFCLRP-USP, Ribeirão Preto, São Paulo, Brazil \\ 3 - Departamento de Zoologia e Botânica, IBILCE-UNESP, São José do Rio Preto, São Paulo, Brazil
}

\author{
Article History \\ Edited by \\ Gilberto M. M. Santos, UEFS, Brazil \\ Received $\quad 11$ September 2017 \\ Initial acceptance 03 October 2017 \\ Final acceptance $\quad 08$ January 2018 \\ Publication date $\quad 09$ July 2018

\section{Keywords} \\ Queen selection, behavior, flexibility, queen \\ elimination.

\section{Corresponding author \\ Laura Chavarría Pizarro \\ Escuela de Biología \\ Instituto Tecnológico de Costa Rica \\ 159-7050, Cartago, Costa Rica. \\ E-Mail: laurachp@gmail.com}

\begin{abstract}
In the Epiponini, queen number declines through colony cycle, because some queens are expelled from colonies. Here we demonstrate that Epiponini wasps may accept expelled queens in situations of queenlessness. One colony of Protopolybia exigua was observed at the University of São Paulo in Brazil; and another of Metapolybia docilis was observed at La Selva Biological Station in Costa Rica. Queen removal tests were performed to study workers' acceptance of expelled queens and queens from other colonies. In $P$. exigua, the experimental queen elimination caused a change in the workers' behavior, ranging from aggressive expulsion of non-selected queens to re-acceptance. In $M$. docilis workers were willing to accept queens from other colonies after queen elimination. Our results indicate that because of a decrease in workers aggressiveness during the colony cycle, workers may accept expelled queens (even foreign ones, in experimental situations) in order to ensure colony survival.
\end{abstract}

Epiponini, a tribe of Neotropical social wasps, presents complex caste differences, which vary from no differences between queens and workers to conspicuous differences (Noll et al., 2004). In addition, colonies have multiple queens which decrease in number through the colony cycle from several (polygyny) to a few (olygogyny), or only one (monogyny) (West-Eberhard, 1978), leading to an increase in kinship among colony mates, as predicted by kin-selection theory (Hamilton, $1964 \mathrm{a}, \mathrm{b}$ ) and reported for several epiponines (see Hastings et al., 1998 for a review). In the first stages of the colony cycle, there are several queens, since more are necessary to produce enough workers to maintain the colony (West-Eberhard, 1978). Nevertheless, as the colony grows queen number diminishes (West-Eberhard, 1978; Noll \& Zucchi, 2000; 2002). New queens will be produced during the reproductive phase or when colony requires, for example, in case of queen loss (Noll \& Zucchi, 2000; 2002). According to West-Eberhard (1978) rejected queens are expelled from colonies by workers, who can distinguish reproductive from non-reproductive females (Naumann, 1970; West-Eberhard, 1977; Nascimento et al., 2004; Chavarria-Pizarro, 2013).

Epiponini wasps are also characterized by their behavioral flexibility, which is evident in certain stages of colony cycle (West-Eberhard, 1978). During periods of a large number of queens, the level of aggressiveness of workers towards them is extremely high and workers perform aggressive displays toward some of them, probably those with less fitness. This was first observed by WestEberhard (1978), who showed that queens who behaved submissively in response to this display are usually removed from the nest. In some cases, the targeted queens remain in the nest and take up worker activities (West-Eberhard, 1978). 
On the other hand, some workers may lay eggs in case of queen loss (Chavarria-Pizarro, 2013) and also replace the queens in some situations (Mateus et al., 1997). It is interesting that the level of aggressiveness is extremely high during the periods of high queen density only and workers are constantly removing non-qualified reproductives. In contrast, during periods of colony orphanage (queenlessness), the need for new reproductives forces workers to be less exigent in terms of reproduction (Noll \& Wenzel, 2008; Noll, 2013), even for a short period of time before new gynes will be produced (Noll, 2013). Consequently, behavioral flexibility is important for colony survival over critical phases. Here we provide observations from two species of Epiponini, Protopolybia exigua and Metapolybia docilis, which indicates that in cases of orphanage these wasps accept expelled queens.

\section{Protopolybia exigua}

One colony of Protopolybia exigua with approximately 50 individuals, was observed from 17/12/2011 to 01/02/2012, twice a week, four hours a day, at the campus of University of São Paulo in Ribeirão Preto, Brazil (21 ${ }^{\circ} 10^{\prime} \mathrm{S}$; $\left.47^{\circ} 48^{\prime} \mathrm{W}\right)$. At the beginning of the observations, the colony was in a period of pre-emergence of adults, phase in which it remained since no adult offspring was produced. In this nest, all queens and a sample of nine workers were individually marked with quick-drying paint. The queens were identified based on the observations of oviposition and bending display behaviors (West-Eberhard, 1978). Queen and worker behavior through colony establishment and pre-emergence phase, was observed during the first month, to determine queen selection dynamics. After four weeks of observation, selected queens (i.e. egg layers which were not expelled from colony by workers) were removed in order to study workers behavior and their flexibility to accept eliminated queens.

During the first week of observations, nine females were observed to behave as queens. After one month, the workers selected three of the nine putative queens, and expelled the remaining $(\mathrm{N}=6)$ using aggressive behaviors (biting) (West-Eberhard, 1978). When the expelled queens tried to access the nest, workers aggressively bit them, forcing these individuals to fly away. After the experimental queen elimination, workers' behavior changed. The unselected queens were not bitten and expelled by workers, which also reaccepted them into the colony.

\section{Metapolybia docilis}

One colony (N-2) of Metapolybia docilis (50 individuals) was observed for three days (23/03/2012 to 25/03/2012), six hours a day, at La Selva Biological Station

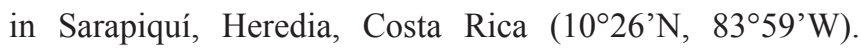
Additionally, other three colonies (N-1, N-3, N-4), with around 100 wasps, were used to obtain individuals to perform treatments. All M. docilis colonies were in the workerproduction stage. A section of nest envelope was cut, and folded back (as a door) every day to perform observations. To identify queens, some eggs were removed from the nest to stimulate oviposition. In colony $\mathrm{N}-2$, five females were observed behaving as queens and all of them were marked.

In order to observe the behavior of wasps, four treatments (T1 to T4) were performed. In T1, two marked workers from nest N-4 were introduced in N-2 to observe workers' and queens' behavior towards foreign individuals. N-2 workers behaved aggressively by biting these foreign individuals. Nevertheless, after few minutes of aggression, N-2 workers carefully groomed the foreign workers for several minutes. After grooming, one N-4 worker flew away, and one was accepted by colony $\mathrm{N}-2$ for one day.

In $\mathrm{T} 2$, four marked queens from N-1 were introduced in N-2 to observe workers' behavior towards "foreign queens" when the original queens were present. Two of these flew away before workers recognized them and two were expelled by workers through aggressive behaviors.

In $\mathrm{T} 3$, four queens of N-3 were introduced to N-2 after the queens' removal (same procedure performed for Protopolybia) to observe N-2 workers' behavior under queen's absence. Unlike in the Protopolybia procedure, the original queens were kept individually in a $50 \mathrm{ml}$ plastic vial where they remained for approximately 24 hours. As in T2, workers at first aggressively bit the foreign queens, but after a few minutes they groomed and accepted three of the four queens for at least one day.

In T4, after 24 hours, the original N-2 queens were re-introduced into their colony to observe workers' behavior towards their own queens. When the original queens (N-2) were reintroduced in T4, they were all accepted (workers did not behave aggressively) into the colony.

Our observations indicate that in both species workers were not willing to accept expelled queens when selected queens were present in the colony. Unlike other insect societies, queen selection is performed by workers in Epiponini (Noll \& Wenzel, 2008), who usually test queens by ritualized behaviors, using their response as an indicator of reproductive capacity (West-Eberhard, 1978; Nascimento et al., 2004; ChavarriaPizarro, 2013). Selected queens are probably recognized by workers as having a higher reproductive capacity. Nevertheless, after selected queens were experimentally removed, workers re-accepted expelled ( $P$. exigua) and foreign queens ( $M$. docilis). Social wasps can recognize queen absence (Nascimento et al., 2004; Chavarria-Pizarro, 2013) and, for this reason, expelled queens were accepted only when queen removal test were performed. If unselected queens have a good reproductive output, or belong to the original swarm, workers could be willing to re-accept them to replace queen(s) loss, as we observed in P. exigua. Similarly, foreign queens of $M$. docilis N-3 may have high reproductive capacity and because N-2 workers could perceive it, they were accepted 
even belonging to another colony. These findings do not oppose kin-selection theory, because orphanage is very likely to lead to colony death. In these scenarios, the possibility of colony survival, even with a cost of lowing the relationship among colony members, is probably adaptive. As mentioned above (see Introduction), low aggressiveness during periods of low queen number may be an important adaptive strategy to allow colony survival, because during orphanage workers with some reproductive potential (intermediates) can assume colony reproduction until new queens can be produced (Noll, 2013). In this scenario, it may be that queens that were previously rejected but remained on the nest acting as workers might find a window to reassume the queen role again. The acceptance of foreign queens by queenless workers shows that workers can recognize they are without a queen and modify their behavior to assure colony survival. It is not known how often queen loss in these species occurs under natural conditions.

Although in $M$. docilis we could not be sure if foreign queens remain permanently in the colony, or, if they were accepted temporarily under queen loss, the workers' behavioral flexibility was evident. These observations indicate that under certain situations it is convenient to accept expelled queens (even foreign queens under experimental conditions), possibly when queen-worker conflicts and the levels of aggressiveness are low. Even when selected queen(s) would be favored over expelled and foreign queens to increase workers' fitness, behavioral flexibility seems to be an important feature because it allows colonies to distribute individuals to perform tasks according to colony needs, and this feature is very important to ensure colony survival (Karsai \& Wenzel, 2000; Nowak et al., 2010).

\section{Acknowledgments}

We especially thank Fundação de Amparo à Pesquisa do Estado de São Paulo (FAPESP) (2009/07526-2; 2011/060585) for financial support; to Organization of Tropical Studies (OTS) for scholarship during Short Course on Neotropical Social Insect Biology; the Entomology graduate program of FFCLRP-Universidade de São Paulo, Brazil; to Sergio Jansen, for field assistance, their comments and suggestions essential for manuscript improvement. We are grateful to the two anonymous reviewers for their suggestions, editing and comments.

\section{References}

Chavarria-Pizarro, L. (2013). Sobre a produção e seleção de rainhas em diferentes fases do ciclo colonial em Epiponini (Vespidae: Polistinae). Dissertation, University of São Paulo, Brazil.

Hamilton, W.D. (1964a). The genetical evolution of social behaviour I. Journal of Theoretical Biology. 7:1-16. doi: 10.1016/0022-5193(64)90038-4
Hamilton, W.D. (1964b). The genetical evolution of social behaviour I. Journal of Theoretical Biology, 7:17-52. doi: $10.1016 / 0022-5193(64) 90039-6$

Hastings, M.D., Queller, D.C., Eischen, F.\& Strassmann, J.E. (1998). Kin selection, relatedness and worker control of reproduction in a large-colony epiponine wasp, Brachygastra mellifica. Behavioral Ecology, 9: 573-581. doi: 10.1093/ beheco/9.6.573

Karsai, I. \& Wenzel, J. (2000). Organization and regulation of nest construction behavior in Metapolybia wasps. Journal of Insect Behavior, 13: 111-40. doi: 10.1023/ A:1007771727503

Mateus, S., Noll, F.B. \& Zucchi, R. (1997). Morphological caste differences in the neotropical swarm-founding Polistine wasps: Parachartergus smithii (Hymenoptera: Vespidae). Journal of the New York Entomological Society, 105: 129-139.

Nascimento, F.S., Tannure-Nascimento, I.C. \& Zucchi, R. (2004). Behavioral mediators of cyclical oligogyny in the Amazonian swarm-founding wasp Asteloeca ujhelyii (Vespidae, Polistinae, Epiponini). Insectes Sociaux, 51: 17-23. doi: 10.1007/ s00040-003-0696-y

Naumann, M.G. (1970). The nesting behaviour of Protopolybia pumilia in Panama (Hymenoptera: Vespidae). Dissertation. University of Kansas, USA.

Noll, F.B. (2013). "Marimbondos": a review on the neotropical swarm-founding polistines. Sociobiology, 60: 347-352. doi: 10.13102/sociobiology.v60i4.347-354

Noll, F. \& Zucchi, R. (2000). Increasing caste differences related to life cycle progression in some neotropical swarmfounding polygynic polistinae wasps (Hymenoptera Vespidae Epiponini). Ethology Ecology \& Evolution, 12: 43-65. doi: $10.1080 / 03949370.2000 .9728322$

Noll, F.B. \& Zucchi, R. (2002). Castes and the influence of the colony cycle in swarm-founding polistine wasps (Hymenoptera, Vespidae, Epiponini). Insectes Sociaux, 49: 62-74. doi: 10.1007/s00040-002-8281-3.

Noll, F.B., Wenzel, J. \& Zucchi, R. (2004). Evolution of Caste in Neotropical Swarm-Founding Wasps (Hymenoptera: Vespidae; Epiponini). American Museum Novitates, 25(3467): 1-24. doi: 10.1206/0003-0082(2004)467<0001:EOCINW>2.0.CO;2.

Noll, F.B. \& Wenzel, J.W. (2008). Caste in the swarming wasps: "queenless" societies in highly social insects. Biological Journal of the Linnean Society, 93: 509-522. doi: 10.1111/j.1095-8312.2007.00899.x.

Noll, F.B. (2013). "Marimbondos": a review on the Neotropical swarm-founding polistines. Sociobiology, 60: 347-354. doi: 10.13102/sociobiology.v60i4.347-354

Nowak, M., Tarnita, C.E. \& Wilson, E.O. (2010). The evolution of eusociality. Nature. Nature Publishing Group,466 (7310): 1057-62. doi: 10.1038/nature09205 
Queller, D.C., Negrón-Stomayor, H.C.R. \& Strassmann, J.E. (1993). Queen number and genetic relatedness in a neotropical wasp, Polybia occidentalis. Behavioral Ecology, 4:7-13. doi: 10.1093/beheco/4.1.7

West-Eberhard, M.J. (1977). The establishment of dominance in social wasps. Proceedings of the International Union for Study of Social Insects. Wageningen; 223-227.
West-Eberhard, M.J. (1978). Temporary Queens in Metapolybia Wasps: Nonreproductive Helpers Without Altruism? Science, 200(4340): 441-443. doi: 10.1126/science.200.4340.441.

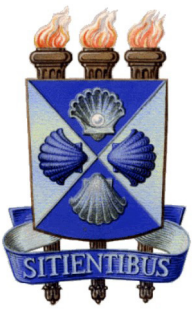

